\title{
CARACTERIZAÇÃO E RECICLAGEM QUÍMICA VIA PIRÓLISE DE RESÍDUOS DA FABRICAÇÃO DE PÁS EÓLICAS
}

\section{CHARACTERIZATION AND CHEMICAL RECYCLING BY PYROLYSIS OF WASTE FROM WIND BLADES MANUFACTURING}

\section{Patrícia Carla Guerrero ${ }^{1}$, Sandro Donnini Mancini ${ }^{2}$, Carim Miguel Toubia ${ }^{3}$}

\author{
${ }^{1}$ Graduanda em Engenharia Ambiental, Universidade Estadual Paulista (UNESP), \\ Campus de Sorocaba. e-mail: patriciacarlaguerrero@gmail.com \\ ${ }^{2}$ Engenheiro de Materiais, Doutor, Professor de Engenharia Ambiental, Universidade \\ Estadual Paulista (UNESP), Campus de Sorocaba. e-mail: \\ mancini@sorocaba.unesp.br \\ ${ }^{3}$ Engenheiro de Materiais, Mestre em Ciência e Tecnologia de Materiais, \\ Universidade Estadual Paulista (UNESP), Campus de Sorocaba. e-mail: \\ carimt@yahoo.com.br
}

\begin{abstract}
RESUMO
A energia eólica é uma forma de energia que seu uso encontra-se em expansão, e junto a esse crescimento, tem-se também o aumento da quantidade de resíduos gerados na fabricação das pás eólicas. Uma forma correta de destinação e aproveitamento desses resíduos é a reciclagem. Porém, esses são constituídos de materiais compósitos, geralmente a resina epóxi e a fibra de vidro; e por possuírem um polímero termofixo (a resina epóxi) na sua composição, a reciclagem convencional via fusão não é possível. Desta forma, a reciclagem química via pirólise apresenta-se como uma alternativa para o aproveitamento desses resíduos, em especial da fibra de vidro que o contém. Após caracterização do resíduo de uma indústria de pás eólicas, verificou-se que se tratava de um material com mais de $70 \%$ de fibra de vidro e muito densas. Foram realizados ensaios de pirólise a seco e com óleo de babaçu, considerado o mais interessante perante vários possíveis e no qual o resíduo fica totalmente imerso, facilitando o inchamento e a troca de calor. Em um sistema de aquecimento com vácuo, foram obtidas mais de $97 \%$ de fibras em 30 minutos a $310{ }^{\circ} \mathrm{C}$, justamente a temperatura em que uma análise termogravimétrica apontou ser a de início de altas taxas de degradação térmica. Palavras-chave: Pirólise. Materiais compósitos. Reciclagem química.
\end{abstract}

\footnotetext{
ABSTRACT

Wind energy is a form of energy that its use is expanding, and with this growth has also increased the amount of waste generated in the manufacture of wind blades. A correct way to use and disposal of these wastes is recycling. However, these are made of composite materials, usually epoxy resin and glass fiber; and by having a thermosetting polymer (the epoxy resin) in their composition, the
} 
conventional recycling by fusion is not possible. Thus, the chemical recycling by pyrolysis is presented as an alternative to the utilization of these wastes, especially glass fiber that they contain. After characterization of the waste from a wind blade industry, it was found that this was a material with more than $70 \%$ glass fiber and very dense. Pyrolysis tests were performed dry and with babassu oil, considered the most interesting face several possible and in which the waste stay completely immersed in facilitating the exchange of heat and swelling. In a heating system with vacuum, were obtained over $97 \%$ of fibers in 30 minutes at $310{ }^{\circ} \mathrm{C}$, exactly the temperature that a thermogravimetric analysis showed to be the start of high rates of thermal degradation.

Keywords: Pyrolysis. Composite materials. Chemical recycling.

\section{INTRODUÇÃO}

Devido às crescentes discussões sobre mudanças climáticas, como por exemplo, o aquecimento global, observa-se que a demanda por formas de energias consideradas renováveis vem ganhando espaço. Dentre essas formas, pode-se citar que a energia eólica, mundialmente é a forma de energia que mais cresce em utilização a cada ano, tendo atingido $152 \mathrm{GW}$ em 2009, o que representa um crescimento de cerca de $25 \%$ no potencial eólico mundial em relação a 2008 (WOBBEN, 2010).

A energia eólica consiste no aproveitamento das massas de ar em movimento (ventos) e para tanto utiliza como equipamento um aerogerador, composto de uma torre de aço ou concreto e normalmente três pás eólicas (LARSEN, 2009).

Já as pás eólicas, são formadas por materiais compósitos, que são materiais multifásicos que exibem uma proporção significativa das propriedades de ambas as fases que o constituem, de tal modo que é obtida uma melhor combinação de propriedades. Eles são constituídos, basicamente, por uma matriz e um reforço, formando um material com propriedades adequadas a inúmeras aplicações, dependendo da combinação das diferentes matérias-primas (De PAOLI, 2008; PINTO, 2002).

Por apresentarem relativo baixo custo e pela combinação de propriedades, os compósitos de resina epóxi (matriz) e fibra de vidro (o reforço) são os materiais utilizados em maior volume atualmente na fabricação das pás eólicas (BRAHMS et al.; LARSEN, 2009).

Associado ao crescimento da energia eólica observa-se também um aumento da quantidade de resíduos gerados na fabricação das pás, assim como, no descarte de pás velhas após o final de sua vida útil. Calcula-se que a vida útil de uma pá eólica é 20 anos e que em 2020 serão geradas aproximadamente 50 mil toneladas anuais de pás usadas em todo o mundo e que esse número só tende a subir, para atingir, em 2034, cerca de 200 mil toneladas anuais (BRAHMS et al.).

Como as pás usadas representam um problema volumoso, pesado e caro, será natural que os proprietários de usinas queiram transferir a solução do mesmo para os fabricantes, e nesse sentido, já se espera legislações internacionais que obriguem o fabricante de pás a dar destino adequado às pás trocadas (BRAHMS et al.; LARSEN, 2009).

Uma solução para esse problema consiste em realizar a reciclagem dos resíduos provenientes da fabricação das pás eólicas. Porém, por possuir um polímero termofixo (polímeros que são moldados na forma de pré-polímero e depois submetidos a um processo de cura, quando assumem sua forma definitiva sem poderem ser moldados novamente por aquecimento), a reciclagem convencional via fusão não é possível. Desta forma, a reciclagem química via pirólise apresenta-se como uma alternativa para o aproveitamento desses resíduos, principalmente da fibra de vidro que estes contém, que pode ser reutilizada na fabricação de piscinas, banheiras, assentos de ônibus e metrô, caixas d'água, reforço de polímeros e até mesmo na fabricação das próprias pás para turbinas eólicas (De PAOLI, 2008). 
A reciclagem química consiste em uma despolimerização, com a formação de monômeros ou outros intermediários úteis a partir de degradações planejadas que resultam na diminuição do peso molecular dos produtos (LA MANTIA, 2002). Pode ser dividida em dois tipos: termólise e solvólise, sendo que a solvólise é baseada no emprego principalmente de solventes para a ocorrência da despolimerização. Já na termólise, a estrutura química do polímero é degradada por meio da ênfase no emprego de calor, e pode ocorrer a partir de três processos: pirólise, gaseificação e hidrogenação (ZANIN et al., 2004).

A pirólise é a degradação térmica de produtos orgânicos, geralmente na ausência de oxigênio para evitar perda de reagentes por combustão, podendo produzir carvão, óleo e gases combustíveis, deixando um resíduo sólido do qual metais e outros materiais sólidos contidos podem ser recuperados, assim como sólidos, líquidos e gases resultantes da degradação. A pirólise tem sido aplicada para uma variedade de resíduos, incluindo pneus, plásticos, biomassa, resíduos sólidos urbanos etc. Geralmente temperaturas altas são usadas, tipicamente no intervalo de 400 a $700^{\circ} \mathrm{C}$ (WILLIAMS, 2010). Os rendimentos de produtos de qualquer processo pirolítico dependem de uma variedade de fatores, como tempo de residência, temperatura, tamanho da partícula do resíduo e a atmosfera utilizada. Dependendo da combinação das condições escolhidas, quantidades variadas de gases, líquidos e sólidos podem ser produzidas (BISIO et al., 1994).

O objetivo deste trabalho é apresentar resultados relativos a tentativas de otimização da pirólise de resíduos da fabricação de pás eólicas, visando à obtenção da fibra de vidro contida e da fração polimérica na forma de um óleo que possa ser aproveitado posteriormente como combustível. Para isso, o material a ser despolimerizado deve ser caracterizado para o correto planejamento das reações de pirólise.

\section{MATERIAL E MÉTODOS}

Utilizou-se amostras (na forma de pó) de refugos da fabricação de pás eólicas coletadas em uma empresa fabricante de pás em Sorocaba-SP, e retiradas de um cilindro, chamado batoque, de 15 $\mathrm{cm}$ de altura e $10 \mathrm{~cm}$ de diâmetro, a partir de sua furação, cuja fotografia pode ser observada na Figura 1. Esta foi realizada em duas direções em relação ao eixo, $0^{\circ}$ e $90^{\circ}$, ou seja, paralelo e perpendicular ao eixo do cilindro.

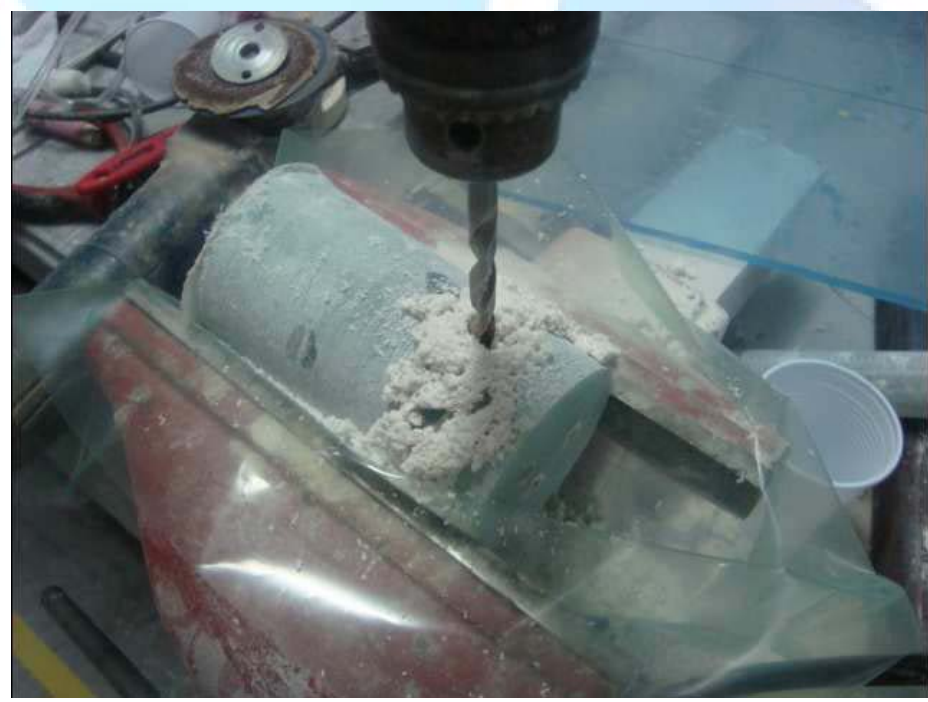

Figura 1. Material utilizado sendo furado 
Para a caracterização do material (amostras a $0^{\circ}$ e $90^{\circ}$ ) foram realizados ensaios de massa específica por picnometria, teor de fibra/ resina e análise termogravimétrica.

Para a medição da massa específica (densidade) foi utilizado um picnômetro Teclabor de $50 \mathrm{~mL}$ previamente calibrado, e de massa conhecida $\left(\mathrm{m}_{0}\right)$, onde inicialmente introduziu-se a amostra. Posteriormente adicionou-se álcool etílico até o picnômetro ficar totalmente preenchido, sendo colocado um papel alumínio previamente pesado na ponta do mesmo para evitar evaporação do líquido. O conjunto permaneceu no refrigerador até que o termômetro acoplado registrasse $23{ }^{\circ} \mathrm{C}$. Então, efetuou-se a pesagem de todo o conjunto, obtendo-se a massa do picnômetro com amostra e líquido $\left(\mathrm{m}_{\mathrm{SL}}\right)$.

Tendo a massa do picnômetro cheio do líquido $\left(\mathrm{m}_{\mathrm{L}}\right)$ e a massa do picnômetro contendo as partículas $\left(\mathrm{m}_{\mathrm{S}}\right)$ e a massa específica do líquido $\left(\rho_{\mathrm{L}}\right)$, calculou-se, então, a massa específica da partícula $\left(\rho_{\mathrm{p}}\right)$ por meio da Equação 1 (GOTOH et al., 1997). A massa específica do líquido $\left(\rho_{\mathrm{L}}\right)$ pode ser calculada com os resultados de $\mathrm{m}_{\mathrm{L}}$ dividido pelo volume exato do picnômetro. Determinou-se que a quantidade de cerca de $1 \mathrm{~g}$ (um grama) de material fornecia resultados repetitivos.

$$
\rho_{P}=\frac{\rho_{L}\left(m_{S}-m_{0}\right)}{\left(m_{L}-m_{0}\right)-\left(m_{S L}-m_{S}\right)}
$$

A determinação do teor de fibra/ resina a partir da queima de orgânicos é uma técnica que consiste no aquecimento da amostra para a remoção da parte orgânica (resina) e a consequente obtenção do reforço (fibra de vidro). Para tanto se utilizou forno-mufla marca Quimis modelo Q318M24 e seguiu-se a norma ASTM D 3171 (2009). Trabalhou-se com uma temperatura máxima de $565^{\circ} \mathrm{C}$ e um tempo de residência total dentro do forno-mufla de 4 horas e 10 minutos.

A análise termogravimétrica (TGA, na sigla em inglês) pode ser entendida como uma técnica analítica na qual a massa de uma determinada substância é constantemente monitorada por uma termobalança, enquanto todo o conjunto é submetido a uma programação controlada de temperatura (MANCINI et al., 2007). Os resultados são obtidos através das curvas termogravimétricas.

A TGA foi realizada para ambas as amostras $\left(0^{\circ}\right.$ e $\left.90^{\circ}\right)$ em equipamento NETZSCH TG 209 F1 do Laboratório de Polímeros do Grupo Schaeffler - INA, sendo aquecidas de 20 a $800{ }^{\circ} \mathrm{C}$ (numa taxa de aquecimento de $20 \mathrm{~K} / \mathrm{min}$ ), empregando-se atmosfera dinâmica de nitrogênio $\left(\mathrm{N}_{2}\right)$.

Foi imaginado que para aumentar a eficiência das reações de pirólise, poderia ser necessário um líquido auxiliar para promover o inchamento do material a ser atacado e melhorar a troca térmica entre as paredes do reator e o pó, embora fosse propósito da pesquisa realizar ensaios sem nenhum líquido para verificar os resultados. Para a determinação de qual seria o mais adequado líquido de pirólise a ser utilizado, analisou-se em diversas referências bibliográficas as características de diversos líquidos, especial a temperatura de trabalho e a densidade. Após a escolha do líquido, este foi adquirido, e realizado uma análise termogravimétrica do mesmo, no mesmo equipamento a $20 \mathrm{~K} / \mathrm{min}$ de 20 a $600{ }^{\circ} \mathrm{C}$, para se ratificar a temperatura que este suporta bem como observar o comportamento térmico do mesmo durante o aquecimento.

Além da caracterização do material e do óleo utilizados, foram realizados quinze testes de pirólise com os seguintes materiais: bomba a vácuo, reator de aço inoxidável com possibilidade de vácuo, chapa de aquecimento, termômetro digital e termopar para a medição das temperaturas. Uma fotografia desse sistema montado pode ser observada na Figura 2. 


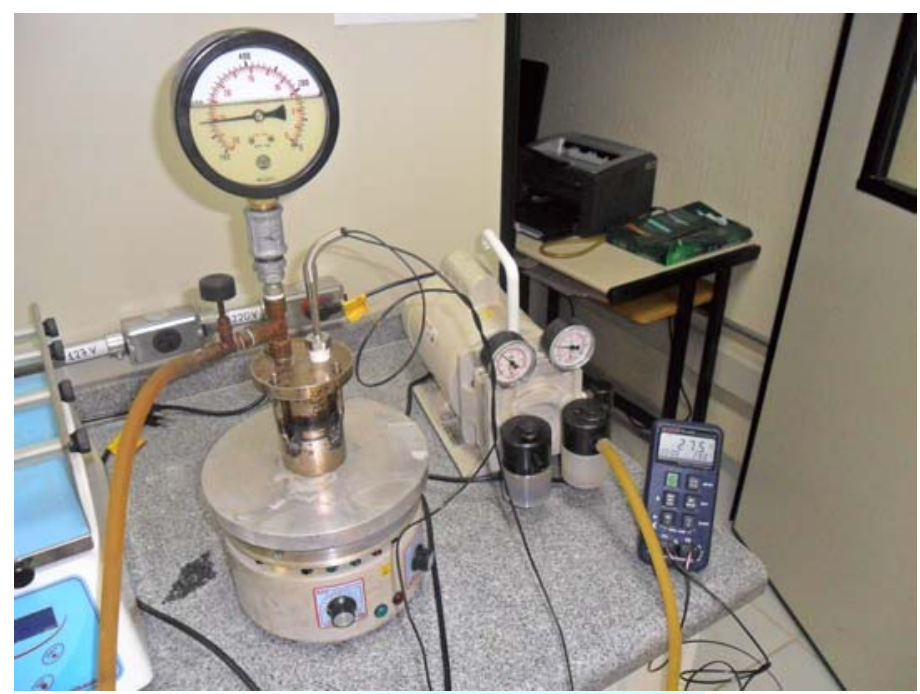

Figura 2. Sistema de pirólise utilizado

Os ensaios de pirólise foram feitos com amostras na direção de $0^{\circ}$ (apenas por uma questão de maior disponibilidade da mesma), variando-se o tempo (30 a 90 minutos após o alcance da temperatura desejada), a utilização ou não do líquido de pirólise, e a temperatura; no caso $210{ }^{\circ} \mathrm{C}$, $215^{\circ} \mathrm{C}, 230{ }^{\circ} \mathrm{C}, 235^{\circ} \mathrm{C}, 240{ }^{\circ} \mathrm{C}, 250{ }^{\circ} \mathrm{C}$ e $310^{\circ} \mathrm{C}$.

Após cada teste de pirólise, determinou-se o teor de fibra/resina das amostras a fim de se comparar com o valor obtido antes da realização deste teste. Antes dessa determinação, as amostras impregnadas com o líquido de pirólise foram lavadas com benzeno ou xileno para a remoção do óleo para que o resultado não sofresse interferência dessa impregnação.

\section{RESULTADOS E DISCUSSÃO}

As Tabelas 1 e 2 apresentam os valores de densidades e teores de fibra/resina obtidos para as amostras de resíduos da fabricação de pás eólicas a $0^{\circ}$ e $90^{\circ}$, respectivamente.

Tabela 1 - Resultados relativos à densidade das amostras $\left(0^{\circ}\right.$ e $\left.90^{\circ}\right)$

\begin{tabular}{|c|c|c|}
\hline \multirow{2}{*}{ Picnômetros } & \multicolumn{2}{|c|}{ Massa Específica (g/cm $\left.{ }^{\mathbf{3}}\right)$} \\
\cline { 2 - 3 } & AMOSTRA 0 & AMOSTRA 90 $^{\circ}$ \\
\hline $1^{\circ}$ & 6,290 & 4,295 \\
\hline $2^{\circ}$ & 6,413 & 3,839 \\
\hline Média \pm Desvio & $6,352 \pm 0,087$ & $4,067 \pm 0,322$ \\
\hline
\end{tabular}


Tabela 2 - Resultados relativos ao teor de fibra/ resina das amostras $\left(0^{\circ}\right.$ e $\left.90^{\circ}\right)$

\begin{tabular}{|c|c|c|}
\hline \multirow{2}{*}{ Cadinhos } & \multicolumn{2}{|c|}{ Teor de Fibra (\%) } \\
\cline { 2 - 3 } & AMOSTRA 0 & AMOSTRA 90 $^{\circ}$ \\
\hline $\mathbf{1}$ & 71,39 & 72,20 \\
\hline $\mathbf{2}$ & 70,83 & 71,97 \\
\hline $\mathbf{3}$ & 71,31 & 71,98 \\
\hline Porcentagem Média Final & $71,18 \pm 0,30$ & $72,05 \pm 0,13$ \\
\hline
\end{tabular}

Pode-se observar que a amostra a $0^{\circ}$ apresentou um valor de densidade maior em relação aos resíduos na direção de $90^{\circ}$, porém ambos os valores foram altos, bem superiores aos dos líquidos de pirólise imaginados (Tabela 3), de forma a sugerir a completa imersão do pó em caso de utilização de um líquido auxiliar para as reações pirolíticas.

Quanto ao teor de fibra/resina encontrado, nota-se que ambos foram parecidos e altos, o que contribui para que seja recuperada uma quantidade considerável de fibra de vidro após a pirólise. O baixo percentual orgânico do resíduo faz com que não seja um promissor candidato à reciclagem energética, em que é forçada a combustão do resíduo visando seu aproveitamento energético.

A Figura 3 mostra as curvas termogravimétricas obtidas para as amostras de $0^{\circ}$ e $90^{\circ}$.

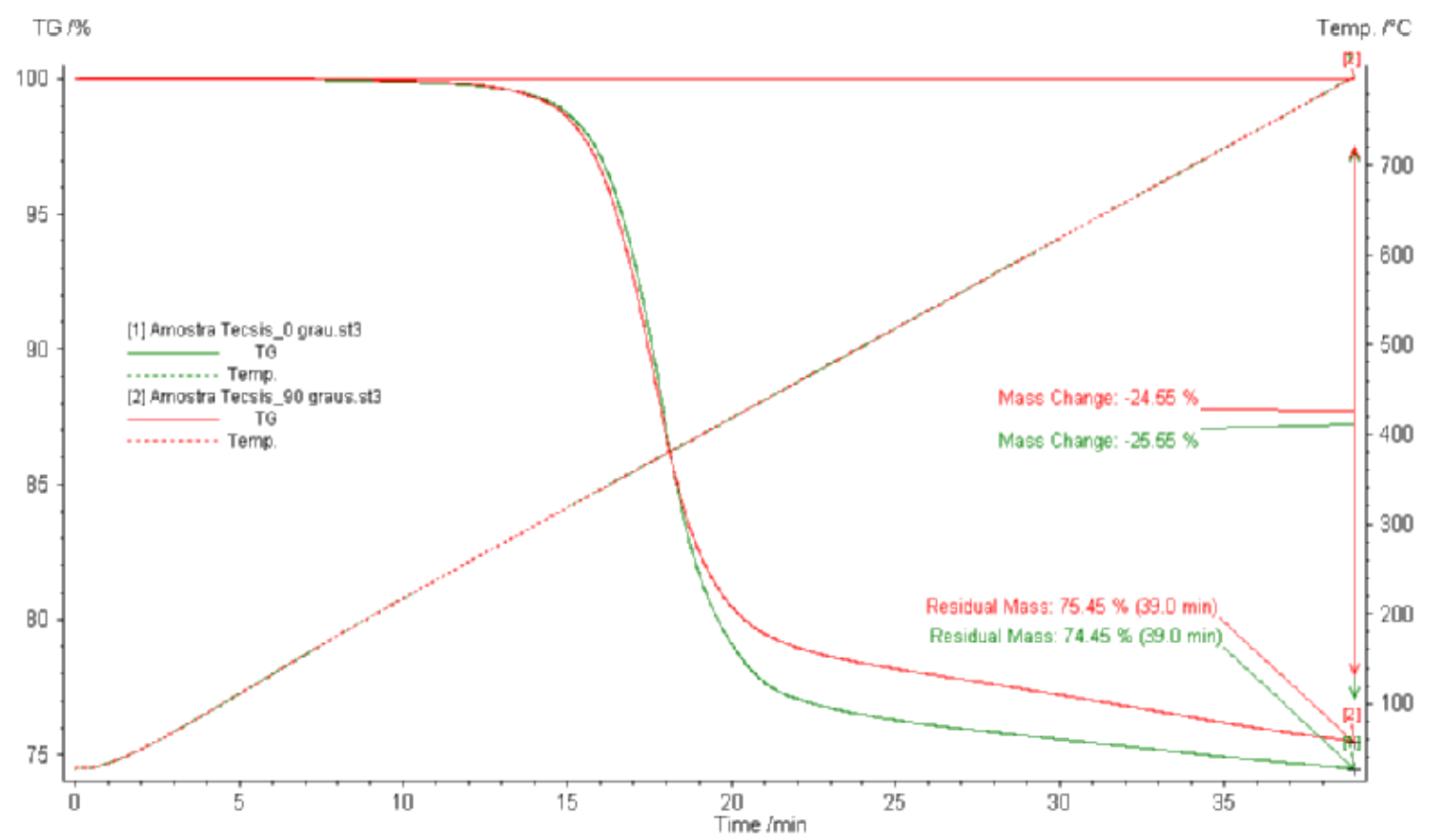

Figura 3. Curvas termogravimétricas das amostras de $0^{\circ}$ (curva verde) e $90^{\circ}$ (curva vermelha) 
A partir das curvas observa-se que a decomposição térmica inicia-se a $310{ }^{\circ} \mathrm{C}$ e que ambas as amostras apresentam curvas termogravimétricas bastante parecidas, sendo que a amostra a $0^{\circ}$ possui uma degradação um pouco maior a uma temperatura acima de $400{ }^{\circ} \mathrm{C}$. Sendo assim, a amostra a $0^{\circ}$ possui uma massa residual menor $(74,45 \%)$ se comparada com a da amostra a $90^{\circ}$ $(75,45 \%)$, porém, valores ainda muito próximos e também similares aos obtidos no ensaio do teor de fibra/ resina (Tabela 2), novamente confirmando o grande percentual de inorgânicos presentes nas amostras. Observa-se também que a degradação do material ocorre de uma forma bastante rápida de temperaturas em torno de 310 a $450{ }^{\circ} \mathrm{C}$, sendo que após esse último valor tem-se uma degradação bastante lenta, dada por completo em $750{ }^{\circ} \mathrm{C}$. Na taxa de aquecimento do ensaio (20K/min), o tempo necessário para completar a degradação foi de aproximadamente 39 minutos.

Mesmo com os resultados da análise térmica, foram realizados ensaios com temperaturas inferiores a $310{ }^{\circ} \mathrm{C}$, em virtude das limitações do sistema empregado. Outra análise térmica realizada com as amostras, no caso a Calorimetria Diferencial Exploratória, determinou que a temperatura de transição vítrea da resina epóxi curada é de cerca de $90{ }^{\circ} \mathrm{C}$. Essa temperatura foi utilizada como limite inferior do ensaio de pirólise, pois acima dela a fase amorfa da estrutura ganha mobilidade, facilitando inchamento, ataques químicos etc. (TOUBIA, 2011).

As características analisadas de diversos líquidos selecionados de revisão bibliográfica podem ser observadas na Tabela 3 .

Tabela 3 - Características de líquidos para a determinação do líquido de pirólise (CONCEIÇÃO et al., 2009; FAGUNDES et al.; GARCIA et al.; JESUS et al., 2008; LIMA et al., 2007; RABELO et al.; ROSENHAIM et al.; SANTOS et al.).

\begin{tabular}{|c|c|c|c|c|c|c|}
\hline \multirow{2}{*}{ Características } & \multicolumn{5}{|c|}{ LÍQUIDOS } \\
\cline { 2 - 7 } & $\begin{array}{c}\text { Óleo } \\
\text { Diesel } \\
\text { Castanha } \\
\text { de Caju } \\
\text { dóleo de } \\
\text { fritura) }\end{array}$ & $\begin{array}{c}\text { Óleo de } \\
\text { Mamona }\end{array}$ & $\begin{array}{c}\text { Óleo de } \\
\text { Soja }\end{array}$ & $\begin{array}{c}\text { Óleo de } \\
\text { Babaçu }\end{array}$ \\
\hline $\begin{array}{c}\text { Temperatura } \\
\text { de Trabalho } \\
\left({ }^{\circ} \text { C) }\right.\end{array}$ & 110 & 200 & 210 & 250 & 300 & 350 \\
\hline $\begin{array}{c}\text { Densidade } \\
(\text { g/cm }\end{array}$ & 0,850 & 2,650 & 0,885 & 0,950 & 0,960 & 0,803 \\
\hline
\end{tabular}

Observa-se que o óleo de babaçu é o líquido mais adequado para ser utilizado como líquido de pirólise, já que apresenta a maior temperatura de trabalho, inclusive superior à do início da fase de maior taxa de degradação da resina termofixa, de $310{ }^{\circ} \mathrm{C}$ (Figura 3). Além disso, assim como os outros líquidos, possui densidade inferior à dos resíduos estudados (Tabela 1), facilitando a completa molhabilidade destes neste óleo.

A Figura 4 apresenta o gráfico obtido da análise termogravimétrica do óleo de babaçu. 


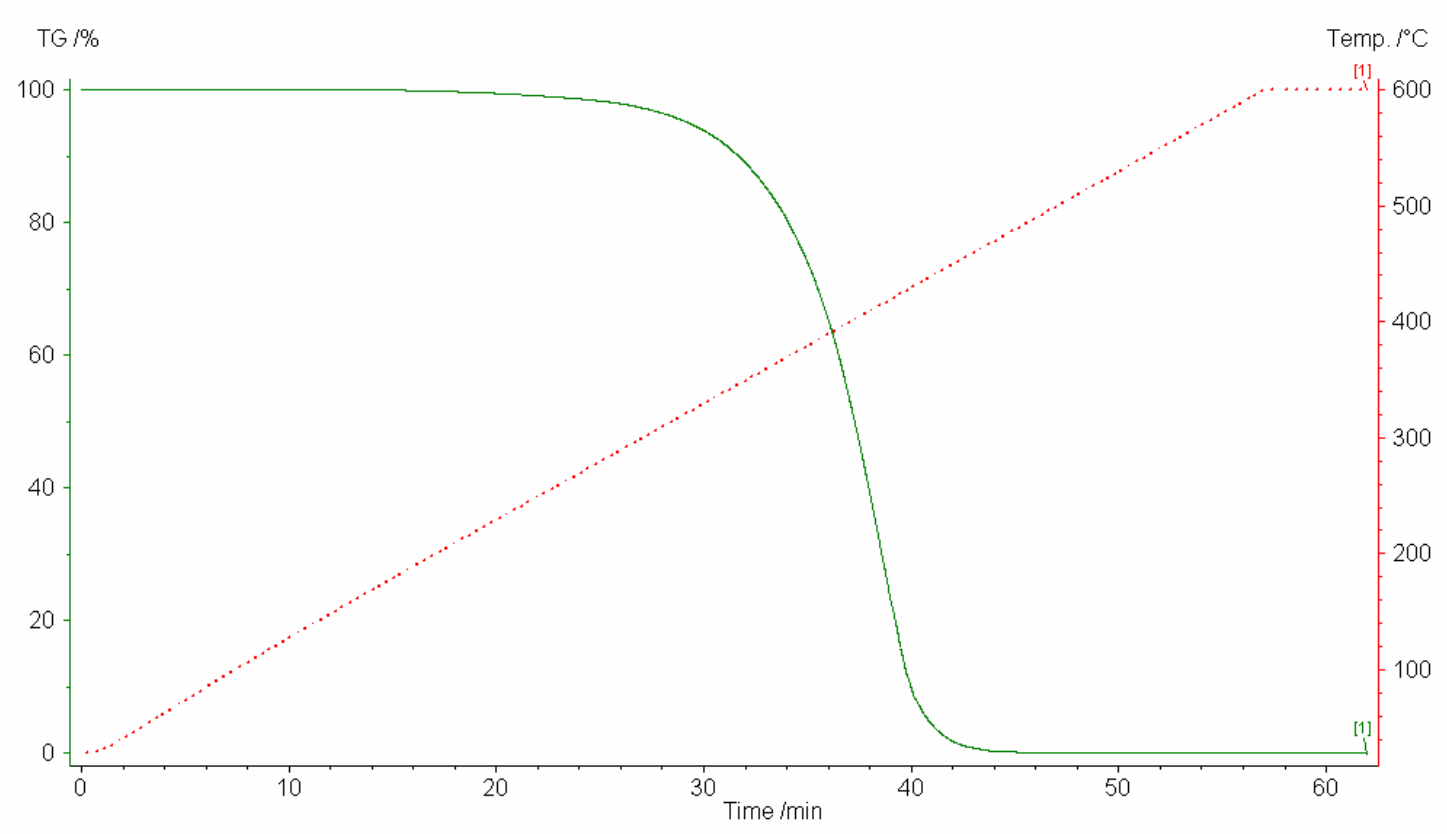

Figura 4. Curva termogravimétrica do líquido de pirólise (óleo de babaçu)

Observa-se, de acordo com a curva termogravimétrica obtida para o óleo de babaçu, que este suporta altas temperaturas $\left(\sim 350{ }^{\circ} \mathrm{C}\right)$, confirmando a possibilidade de sua utilização em temperaturas superiores às do início da degradação térmica do resíduo $\left(310^{\circ} \mathrm{C}\right)$, como observado na Figura 3. Nota-se também que a degradação do óleo ocorre em uma única etapa, e de uma forma bastante rápida, de temperaturas em torno de 350 a $450^{\circ} \mathrm{C}$. Após esse último valor, tem-se que a curva termogravimétrica apresenta-se constante. Na taxa de aquecimento do ensaio $(20 \mathrm{~K} / \mathrm{min})$, o tempo necessário para completar a degradação foi de aproximadamente 45 minutos.

Assim, a temperatura de $350{ }^{\circ} \mathrm{C}$ deve funcionar como a máxima a ser testada em reações de pirólise utilizando-se óleo de babaçu como líquido auxiliar para que o óleo mantenha sua integridade e, consequentemente, propriedades.

A Tabela 4 apresenta os parâmetros utilizados nos ensaios de pirólise (temperatura, tempo, utilização ou não do líquido de pirólise), além dos teores de fibra de vidro encontrados para as amostras pós pirólise.

Tabela 4 - Resultados relativos aos testes de pirólise e teores de fibra de vidro.

\begin{tabular}{|c|c|c|c|c|}
\hline Ensaios & $\begin{array}{c}\text { Temperatura } \\
\left({ }^{\circ} \mathrm{C}\right)\end{array}$ & Tempo (min.) & $\begin{array}{c}\text { Líquido de } \\
\text { Pirólise }\end{array}$ & $\begin{array}{c}\text { Teor de Fibra } \\
(\%)\end{array}$ \\
\hline $1^{\circ}$ & 210 & 30 & - & 73,71 \\
\hline $2^{\circ}$ & \multirow{3}{*}{215} & 30 & - & 79,33 \\
\hline $3^{\circ}$ & & 60 & - & 79,18 \\
\hline $4^{\circ}$ & & 30 & Óleo de babaçu & 73,85 \\
\hline $5^{\circ}$ & \multirow{2}{*}{230} & 30 & - & 79,89 \\
\hline $6^{0}$ & & 60 & - & 79,92 \\
\hline
\end{tabular}




\begin{tabular}{|c|c|c|c|c|}
\hline $7^{\mathbf{o}}$ & 235 & 30 & - & 72,38 \\
\hline $8^{\circ}$ & \multirow{2}{*}{240} & 30 & - & 81,34 \\
\hline $9^{\circ}$ & & 90 & - & 80,04 \\
\hline $10^{\circ}$ & \multirow{2}{*}{250} & 60 & Óleo de babaçu & 94,05 \\
\hline $11^{\circ}$ & & 30 & Óleo de babaçu & 93,59 \\
\hline $12^{\circ}$ & \multirow{4}{*}{310} & 30 & - & 81,07 \\
\hline $13^{\circ}$ & & 60 & - & 84,39 \\
\hline $14^{\circ}$ & & 90 & Óleo de babaçu & 88,05 \\
\hline $15^{\circ}$ & & 30 & Óleo de babaçu & 97,41 \\
\hline
\end{tabular}

Nota-se que os teores de fibra de vidro apresentaram-se sempre superiores após a pirólise em comparação ao valor obtido para a amostra a $0^{\circ}(71,18 \%)$ antes da realização deste teste, o que denota a eficiência da pirólise na recuperação do reforço (fibra). Além disso, essa eficiência também pode ser confirmada pelo resultado do $15^{\circ}$ teste que apresentou o maior de teor de fibra de vidro $(97,41 \%)$, bem próximo dos $100 \%$ desejados.

Observa-se também que as variáveis utilizadas influenciam diretamente na pirólise, sendo que, geralmente, maiores valores de temperatura e tempo contribuem para um melhor aproveitamento do resíduo, ou seja, resultam em maiores porcentagens de fibra de vidro.

O óleo de babaçu como líquido de pirólise teve uma influência positiva durante os ensaios, provavelmente provocando o inchamento do resíduo, facilitando o ataque do mesmo durante a reação; como pode ser observado nos testes 10,11 e 15 , onde se obteve maiores porcentagens de fibra e se utilizou o líquido.

Apesar de serem necessários testes que assegurem a reprodutibilidade do sistema reacional e da definição de comportamentos cinéticos da reação, os resultados da Tabela 4 são bastante interessantes ao mostrar que a pirólise deste tipo de resíduo é possível, assim como é a recuperação da fibra presente. Isso porque a máxima temperatura utilizada, $310{ }^{\circ} \mathrm{C}$, corresponde ao início da região de altas taxas de degradação da resina epóxi curada. Temperaturas até $350{ }^{\circ} \mathrm{C}$ podem ser testadas com o óleo de babaçu, ou superiores sem óleo ou com outro líquido mais estável termicamente, e tendem a acelerar ainda mais a completa despolimerização da resina.

\section{CONCLUSÕES}

Por meio dos resultados obtidos e dos procedimentos metodológicos aplicados, conclui-se que a reciclagem química via pirólise apresenta-se como uma boa alternativa para reciclagem dos resíduos da fabricação de pás eólicas, sendo eficiente para o aproveitamento dos mesmos, a partir da recuperação da fibra de vidro que o contém, a qual pode ser reutilizável. Esse fato pode ser 
ratificado pela porcentagem de fibra de vidro obtida após a pirólise, que alcançou mais de $97 \%$ do valor teoricamente possível.

Nesse contexto, observa-se também que a utilização do óleo de babaçu, como líquido de pirólise contribui para a transferência de calor do reator para o resíduo e inchamento do mesmo, facilitando a reação.

\section{AGRADECIMENTOS}

Os autores agradecem à Fundação de Amparo à Pesquisa do Estado de São Paulo (FAPESP) pelo financiamento, à Tecsis - Tecnologia e Sistemas Avançados Ltda., Eduardo Murbach Jr. e à Schaeffler INA pelo apoio em vários momentos da pesquisa.

\section{REFERÊNCIAS}

BISIO, A. L.; XANTHOS, M. How to Manage Plastics Waste: Tecnology and Market Opportunities. Munich; Vienna; New York: Hanser; Cincinnati: Hanser/ Gardner, 1994.

BRAHMS, T.; KUME, U.; ALBERS, H. e GREINER, S. Feasibility study for the recycling of composite material. Disponível em: $<\mathrm{http}: / / \mathrm{www}$.faserverbund-verwertung.de/ $>$. Acesso em: 27 jul. 2011.

CONCEIÇÃO, M. M.; DANTAS, M. B.; ROSENHAIM, R.; FERNANDES JR, V. J.; SANTOS, I. M. G.; SOUZA, A. G. Evaluation of the oxidative induction time of the ethilic castor biodiesel. J Term Anal Calorim, v.97, p.643-646, 2009.

De PAOLI, M. A. Degradação e Estabilização de Polímeros. São Paulo: Artliber Editora, 2008.

FAGUNDES, F. P.; BEZERRA, J. P.; GARCIA, M. A.; MEDEIROS, A. C. R.; BORGES, M. R.; GARCIA, R. B.; COSTA, M. Avaliação das Propriedades do Óleo de Mamona na Produção de Biocombustível. Disponível em: $<\mathrm{http}$ :/www.portalabpg.org.br/PDPetro/-

3/trabalhos/IBP0617_05.pdf>. Acesso em: 06 jul. 2010.

GARCIA, C. C.; COSTA, B. J.; VECHIATTO, W. W. D.; ZAGONEL, G. F.; SUCHEK, E. M.; ANTONIOSI FILHO, N. R.; LELES, M. I. G. Estudo Comparativo da Estabilidade Oxidativa de Diferentes Biodiesel por Termogravimetria (TG) e Teste Rancimat. Disponível em: $<$ http://www.biodiesel.gov.br/docs/congressso2006/-Caracterizacao/EstudoComparativo7.pdf $>$. Acesso em: 06 jul. 2010.

GOTOH, K.; MASUDA, H.; HIGASHITANI, K. (Ed.). Powder Techonolgy Handbook. 2. ed., Nova Iorque, Editora Marcel Dekker Inc., 1997, 944 p.

JESUS, V. L. B.; PALMA, D. A. Medição da densidade do óleo: uma discussão sobre sua otimização e diminuição dos custos via incerteza relativa da medição. Rev. Bras. Ensino Fís., São Paulo, v. 30, n.3, set. 2008. Disponível em: <http://www.scielo.br/scielo.php?script=sci_arttext\&pid=S180611172008000300002\&lng=pt\&nrm=iso $>$. Acesso em: 04 jul. 2010.

LA MANTIA, F. Handbook of Plastics Recycling. U. K: Rapra Technology Limited, 2002. 442 p. 
LARSEN, K. Recycling Wind Turbine Blades. Renewable Energy Focus, v.9, n.10, p.70-73, 2009.

LIMA, J. R. O.; SILVA, R. B.; SILVA, C. C. M.; SANTOS, L. S. S.; SANTOS, J. R.; MOURA, E. M.; MOURA, C. V. R. Biodiesel de babaçu (Orbignya sp.) obtido por via etanólica. Quím. Nova, São Paulo, v.30, n.3, p.600-603, 2007. Disponível em: <http://www.scielo.br/scielo.php?script=sci_arttext\&pid=S010040422007000300019\&lng=en\&nrm=iso $>$. Acesso em: 06 jul. 2010 .

MANCINI, S. D.; NOGUEIRA, A. R.; KAGOHARA, D. A.; SCHWARTZMAN, J. A. S.; MATTOS, T. Análises Termogravimétricas de Composto Orgânico Produzido com Restos de Comida e Lixo de Jardim. In: 24o CONGRESSO BRASILEIRO DE ENGENHARIA SANITÁRIA E AMBIENTAL, 2007, Belo Horizonte-MG. Anais... em CD-ROM. Rio de Janeiro-RJ: Associação Brasileira de Engenharia Sanitária e Ambiental, 2007.

PINTO, K. N. C. Reciclagem de resíduos de materiais compósitos de matriz polimérica: poliéster insaturado reforçado com fibras de vidro. Instituto de Pesquisas Energéticas e Nucleares, São Paulo, 2002, 81 p. Disponível em:

$<$ http://pelicano.ipen.br/PosG30/TextoCompleto/KellyNanciCarneiroPinto.pdf>. Acesso em: 01 ago. 2011.

RABELO, A. N.; BARROSO, S. H. A.; SOARES, S. A.; SOARES, J. B.; NASCIMENTO, D. R. Estudos Preliminares sobre a Adição do Líquido da Castanha de Caju ao CAP para Aplicação em Serviços de Imprimação. Disponível em:

$<$ http://www.redeasfalto.org.br/index2.php?option=com_docman\&task=doc_view\&gid=228\&Itemi $\mathrm{d}=27>$. Acesso em: 06 jul. 2010.

ROSENHAIM, R.; TAVARES, M. L. A.; CONCEIÇÃO, M. M.; LIMA, A. E. A.; SANTOS, I. M. G.; SOUZA, A. G. Estudo por Termogravimetria do Biodiesel de Origem de Óleos Vegetais Usados, Misturas B5, B10, B15, B20 e B25 e Diesel Mineral. Disponível em:

$<$ http://www.biodiesel.gov.br/docs/congressso2006/Armazenamento/EstudoTermogravidade4.pdf $>$. Acesso em: 06 jul. 2010.

SANTOS, R. B.; SERRATE, J. W.; CALIMAN, L. B.; LACERDA JR, V.; CASTRO, E. V. R. Avaliação do Uso de Óleo Residual Usado em Fritura para a Produção de Biodiesel e Estudo da Transesterificação de Óleo de Soja com Álcoois de Cadeia de até Quatro Carbonos. Departamento de Química, Universidade Federal do Espírito Santo. Disponível em:

$<$ http://www.biodiesel.gov.br/docs/congresso2007/producao/10.pdf>. Acesso em: 04 jul. 2010.

TOUBIA, C. M. Estudo sobre as Possibilidades de Recuperação de Resíduos Provenientes da Fabricação de Pás Eólicas. 2011. 149 f. Dissertação (Mestrado em Ciência e Tecnologia de Materiais). Universidade Estadual Paulista, Sorocaba-SP, 2011.

WILLIAMS, P. T. Valorization of Printed Circuit Boards from Waste Electrical and Electronic Equipment by Pyrolysis. Waste Biomass, v.1, p.107-120, 2010.

ZANIN, M.; MANCINI, S. D. Resíduos Plásticos e Reciclagem: Aspectos gerais e tecnologia. São Carlos: Edufscar, 2004. 143 p. 